\title{
UK DENTAL SCHOOLS TO PROVIDE ALTERNATIVE SOLUTION FOR STUDENTS TAKING FINAL EXAMS
}

Dental schools in the UK are enabling students in their final year to take final exams through online systems, according to a recent joint statement issued by the GDC. Students who are ill or self-isolating also currently have the option of taking their exams at an alternative date in some schools.

For undergraduates, the statement read: 'While most undergraduate courses in the UK are not due to finish for another two to three months, many, if not most, students have completed the necessary education, training and assessment to enable them to sit final exams. However, due to the COVID-19 outbreak, face to face final exams will not take place as scheduled.

'Dental schools and universities are now establishing online systems to enable final exams to be sat for undergraduate students in their final year of study. Arrangements are also being made by some schools to enable more than one sitting of final exams. This is so that those who are ill or self-isolating, on the date of the final exam, will be able to sit their exam on an alternative date.

'The small number of students who are fit to practise as 'safe beginners', but who have a potential area of weakness or lack of experience identified by their school, will be provided with a development plan by the relevant dental school.

'Those who are not ready to sit final exams will be informed by their school.

'Some dental schools have advised that there may be the facility for further assessments, including resits in November. However, this is subject to need and the necessary arrangements being put in place.'

Foundation training places for graduating students will be announced as normal on 12 June, and for the time being placements will

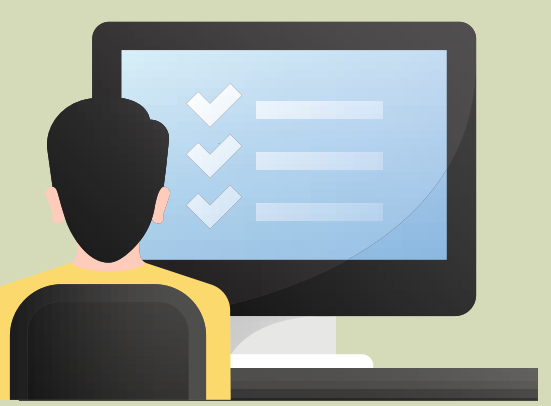

start as normal in September, or in August for those in Scotland.

The GDC has reminded students that they will only have a few weeks to complete their GDC registration, which they will need in order to start their foundation or vocational training placement in the autumn. According to the GDC there will not be a delay in processing applications as their staff will be working remotely.

\section{NEW SAFE BRACE CAMPAIGN ALERTS PATIENTS TO THE DANGERS OF 'DIY BRACES'}

The Oral Health Foundation and British Orthodontic Society have launched Safe Brace (www.safebrace.org) - a campaign to give people a trusted space they can go to for expert advice on getting braces and orthodontic treatment.

The launch of Safe Brace follows a statement from the General Dental Council (GDC) expressing concerns over direct-to-consumer orthodontics and stressing the importance of always seeing a trained profession face-to-face when seeking dental treatment.

Dr Nigel Carter OBE, Chief Executive of the Oral Health Foundation, said: 'We are highly concerned by the growth of companies offering orthodontic treatment online. Many of these providers lure people in with cheap prices and the promise of fast results.

'Straightening teeth is a highly complex medical procedure and should only be carried out by a dentist or orthodontist. These faceto-face appointments are essential. They allow for a patient to be fully assessed by a qualified professional who can help guide them arrive at the most appropriate treatment for their needs. Importantly, the dentist will also be able to monitor a person's progress throughout the course of their treatment and make adjustments to the appliance when needed.

'By visiting a trained clinician, patients will get a full examination and have a range of different treatment options explained to them. This will put the patient in a great position to get the best results in a safe and effective environment. It will also mean that the treatment is more likely to meet a patient's expectations.

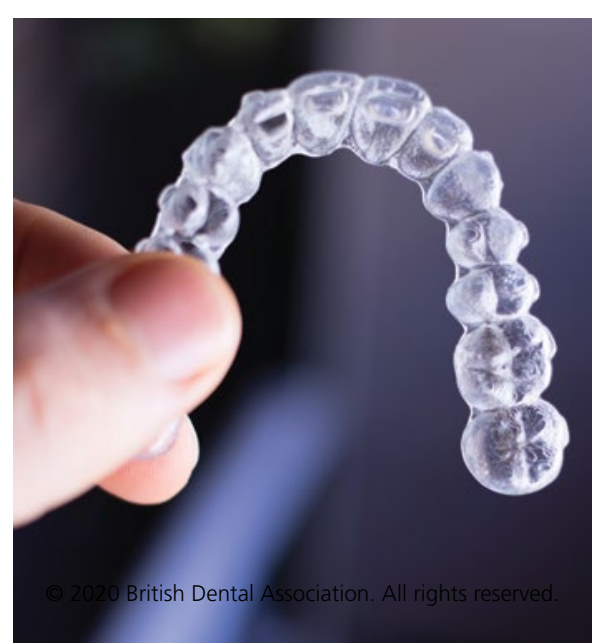

'The consequences of ill-fitting braces are hefty and can leave a person with permanent damage to their teeth, gums and jaw. As part of Safe Brace, we will be working alongside the British Orthodontic Society to protect the health of all people undergoing dental treatment.'

Recent statistics from the British Orthodontic Society highlight the rise in demand for orthodontic treatment in Britain. According to the charity, three in four (75\%) of orthodontists report an increase in adult private patients.

Professor Jonathan Sandler, President of the British Orthodontic Society, said: 'In my professional opinion, if you embark on any orthodontic treatment without a suitably trained clinician taking the time to examine you and make appropriate recommendations, you could be in danger of having serious conditions missed, as well as inappropriate and dangerous treatment carried out.

'What other transforming dental or medical treatment would you undergo, without an inperson evaluation or supervision by a medical professional?

'For me, one of the issues with 'DIY Braces' is that it offers just one narrow solution when there may be a more appropriate one for the patient. The value of informed choice cannot be over-estimated. 